\title{
Boundary Layer Characteristics over Aindanda Low-Mountain Pass of Kathmandu Valley, Nepal
}

\author{
Saraswati Shrestha, Sajan Shrestha, Sangeeta Maharjan and Ram P. Regmi* \\ National Atmospheric Resource and Environmental Research Laboratory (NARERL), Central Department of Physics, \\ Tribhuvan University, Kirtipur, Kathmandu, Nepal. \\ *E-mail:ram.p.regmi@gmail.com
}

\begin{abstract}
The early monsoon time boundary layer characteristics prevailing over Aindanda low-mountain pass of Kathmandu valley has been continuously monitored for the period of 11 to 24 June 2013. The study reveals that the Aindanda pass channels regional air masses from the western neighboring valley up into the Kathmandu valley as westerly/ northwesterly winds during the daytime whereas it drains air mass out of the valley during nighttime. The speed of the westerly/northwesterly wind over the pass often exceeds $6.5 \mathrm{~ms}^{-1}$ during the late afternoon. Nighttime mixing layer height (MLH) was highly fluctuating with an average around 300m whereas daytime MLH was suppressed limiting it in between $290-450 \mathrm{~m}$ above the ground in early part of the day but reduced to $210-270 \mathrm{~m}$ during the late afternoon. Comparison of diurnal variation of mixing layer height at Aindanda with that of the central area of the valley floor strongly suggests that air mass intruding into the Kathmandu valley through this pass is a cool density flow over the weakly stratified mixed layer of valley. The structure of the wind channeled through this pass indicates the possibility of making hydraulic jump in the western part of the Kathmandu valley, particularly, during the late afternoon time.
\end{abstract}

Keywords: Mountain valley, Gap flows, hydraulic jump, boundary layer, mixing layer height, sodar.

\section{INTRODUCTION}

Kathmandu valley, located in a rather isolated mountainous area in the middle hills of Central Nepal Himalaya, is completely enclosed by high mountains and hills except a few low-mountain passes and a river gorge in the southwest rim of the valley (Fig. 1). The meteorological flows associated with this valley can be expected to be complex enough. The valley is said to be executing the plateau-basin dual nature - a rarely reported behavior. It behaves as plateau during the daytime by bringing the regional air masses up into the valley while as basin by forming a deep calm cold air pool during the night (Regmi et al. 2003). The prominent wind systems over the valley have been identified as the relatively cooler southwesterly that intrudes into the valley via southwestern low-mountain passes and the river gorge and the warmer northwesterly that intrudes from the western low-mountain passes. These winds commence close to the noontime and continue to prevail until early evening. These two wind systems merge into a westerly over the center of the valley and channels into the eastern neighboring valley (Regmi et al. 2003). These numerically predicted behaviors of prevailing wind systems over the valley, particularly, the structure, magnitude, diurnal periodicity and their implications are yet to be validated with extensive field observations.
Of the two prominent wind system of the valley, the northwesterly intruding from the central low-mountain pass-the Aindanda in the western rim of the valley is of particular interest for the present study as it is the busiest domestic gateway of Kathmandu Airport from where all the takeoff and landing of light aircrafts for western Nepal are constrained to cross the pass at very low level and the wind channeling through the pass is said to be making hydraulic jump in the western part of the valley (Regmi et al. 2003) thereby putting the light aircrafts at high risk of severe discomfort if not leaded to meet with fatal accident. A couple of fatal accidents have already been witnessed and serious flight discomforts are frequently reported while crossing the pass. Moreover, the northwesterly channeled through this pass also said to be relatively warm and cause daytime thermal inversion over the central and eastern area of the valley and hence set the basic course of air pollution transport and transformation in the valley. However, to the best knowledge, no significant observations have been carried out to understand the vertical structure of this wind and the associated boundary layer characteristics as well as to validate the aforementioned characteristics of the northwesterly wind. 


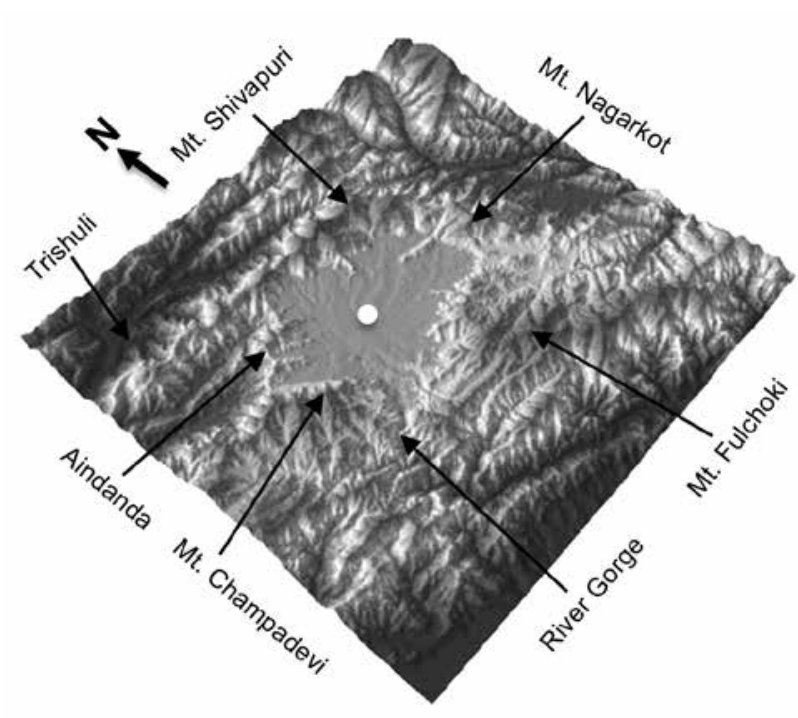

Fig. 1. The three-dimensional topographic view of Kathmandu valley and its immediate surroundings. Important locations including the site of sodar measurement, Aindanda, the western low-mountain pass and the center of the valley (white circle) are also indicated.

Among various instruments available in the field of atmospheric research, sodars are advanced and very powerful acoustic instruments for remote measurements of the three-dimensional wind speed, wind direction, wind shear and turbulence characteristics in the lower atmosphere. Aided with the information provided by sodar, detailed observation and understanding of a boundary layer may be achieved. Because of their low cost, versatility, portability and ability to operate unattended for long periods of time, they have been extensively used in various terrain structures for various purposes. For example, sodars have been used to study coastal land-/sea breeze circulations (Aggarwal et al. 1980, Bacci et al. 1984, Prakash et al. 1992), the Antarctic stable boundary layer (King et al. 1989, Argentini et al. 1992), wind flow in complex terrain (Neff 1988, Neff \& King 1987, 1988), gravity waves (Einaudi et al. 1987, Cheung \& Little 1990, Ralph et al. 1993), low-level jets (Kataoka et al. 1991, Kotroni et al. 1994), and frontal passages (Gera \& Weill 1987, 1991). Techniques have been developed to derive turbulence parameters such as the sensible heat flux (Sen Gupta et al. 1986), turbulence kinetic energy budget (Greenhut \& Mastrantonio 1989), and temperature structure functions (Moulsley et al. 1981, Singal et al. 1982). Sodars are also used in determining mixed layer height (Russell \& Uthe 1978, Coulter 1979, Beyrich 1995, Asimakopoulos et al. 2004, Emeis et al. 2008).

In this paper we will report the boundary layer (Stull 1989) activities leading to the typical characteristics of the gap wind channeled by the Aindanda low-mountain pass as revealed by the sodar observation from the premises of Nepal Army Post at Aindanda. Of all, our approach is to pick basic sodar plots like wind speed, wind direction and backscatter intensity, to add some valuable efforts over previous studies based on numerical simulations like Regmi et al. (2003).

\section{INSTRUMENTATION/ METHODOLOGY}

An advanced monostatic flat array Doppler Sonic Detection and Ranging (sodar) system (MFAS64 Scintec Co., Germany) was installed at Aindanda and configured to measure 15-min averaged profiles of wind speed and direction. Winds were measured from $30 \mathrm{~m}$ above ground level up to $800 \mathrm{~m}$ with the vertical resolution of $10 \mathrm{~m}$. It was operated continuously from 11 to 24 June 2013.

Sodar operation (Brown \& Hall 1978, Neff \& Coulter 1986, Clifford et al.1994) is based on the principle of acoustic backscattering. Sodars are available in monostatic and bi-static arrangement. The MFAS64 sodar (Fig. 2), deployed in this study, is a monostatic sodar and hence it uses the same antenna for emission and reception of sound backscattered at an angle of $180^{\circ}$.

Transducers/antenna emits short sound pulses, which are directed towards the atmosphere and backscattered at temperature inhomogeneities in the air. The antenna then receives the echoed sound pulses and the amplitude and frequency of the backscattered waves are evaluated. The equation of scattering cross section for backscattering is given as

$$
\sigma=0.0039 k^{\frac{1}{3}}\left(\frac{C_{T}{ }^{2}}{T_{0}{ }^{2}}\right)
$$

Where acoustic wavenumber, $k=\frac{2 \pi}{\lambda}, C_{T}{ }^{2}$ is the temperature structure function constant, $\lambda$ is acoustic wavelength and $\mathrm{T}_{0}$ is local temperature. From equation (1) it can be inferred that backscattering depends only on temperature fluctuation and hence the temperature structure of the wind flows can also be assessed (Neff 1990). Backscattering is effective only for turbulent sizes fulfilling the Bragg condition, i.e. where the spatial wave number of the turbulent temperature fluctuations equals to $2 \mathrm{k}$.

In operation, the sodar generates different beam angles during emission and reception by phase-delayed driving and sensing, respectively, of the rows or columns of an array of acoustic transducers. The phase-delayed in the emission and reception mode are produced digitally for long-term stability of phase shifts. The vertical height is gathered by range gating, i.e., by considering the time the pulse needs to propagate from the antenna to the measured layer and back to the antenna. measured layer and back to the antenna. 


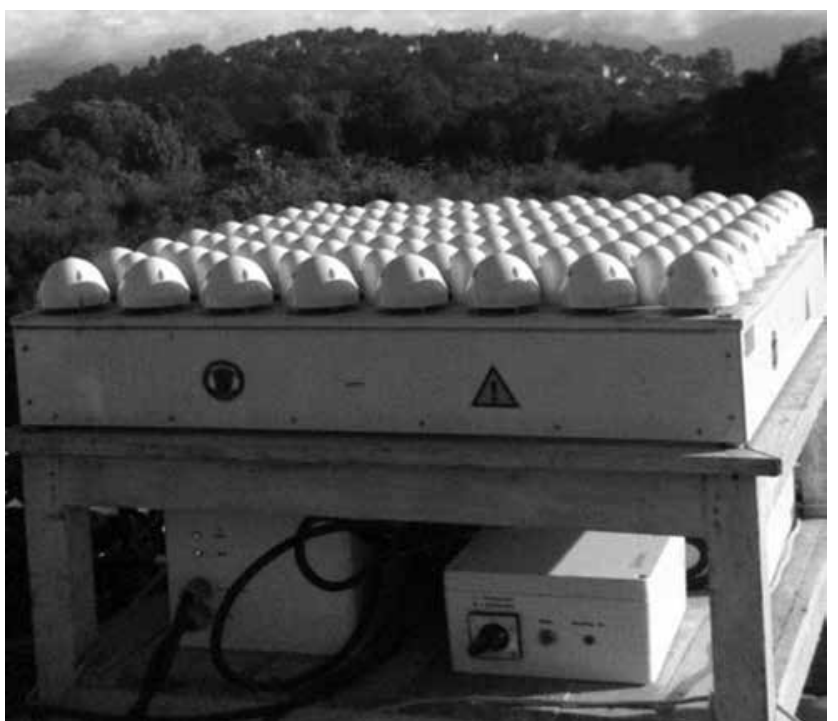

Fig. 2. The MFAS64 Sodar antenna setup on a wooden table with power supply, antenna heating systems and signalprocessing unit.

The amplitude and hence the intensity of the backscattered wave provides the detail information on the turbulent structure in the atmospheric boundary layer. The wind speed is derived from the spectrum of backscattered waves since movement of scattering temperature inhomogeneities with the mean wind causes shift in frequencies of acoustic waves via the so-called the Doppler frequency shift. Thus, when the acoustic sounds are emitted, at least, in three different directions, a vertical profile of the three dimensional wind vectors can be derived. MFAS64 sodar system uses the method of so-called Fast Fourier Transform to analyze the spectrum of backscattered acoustic signals.

The magnitude of the frequency shift with the frequency and the vertical wind speed is given by

$$
\delta f_{v}=-2 \frac{w}{c} f_{v}
$$

It shows that the frequency shift $\delta f_{v}$ is proportional to vertical wind component $w$.

If we consider a beam with frequency $f_{k}$, which is tilted from vertical by an angle $\theta$ into some direction and $\xi$ is the horizontal wind component in that direction, the generalized equation for frequency shift may be written as

$$
\delta f_{\xi}=-2 \frac{\xi}{c} f_{\xi} \sin \left(\theta_{\xi}\right)-2 \frac{w}{c} f_{\xi} \cos \left(\theta_{\xi}\right)
$$

Form this equation we can derive the necessary equation for multi-beams. MFAS64 system can be set to emit and receive acoustic pulses up to nine different directions. Since emission in at least three different directions is required to measure vertical profile of three-dimensional wind, here we present the equations for three-beam case. If we assume one of frequency is tilted from the vertical by an angle into eastern direction, and the other frequency which is tilted from the vertical by an angle into northern direction and a vertical beam with frequency and the three-dimensional wind to be equal in each beam at the respective layers, the easterly wind speed, the northerly wind speed and the vertical wind speed $w$ are calculated from the frequency shifts via

$$
\begin{aligned}
& u=-\frac{\delta f_{E}}{2 f_{E}} \frac{c}{\sin \left(\theta_{E}\right)}+\frac{\delta f_{V}}{2 f_{V}} \frac{c}{\tan \left(\theta_{E}\right)} \\
& v=-\frac{\delta f_{N}}{2 f_{N}} \frac{c}{\sin \left(\theta_{N}\right)}+\frac{\delta f_{V}}{2 f_{V}} \frac{c}{\tan \left(\theta_{N}\right)} \\
& w=-\frac{\delta f_{v}}{2 f_{v}} c
\end{aligned}
$$

Where $c$ is the velocity of sound and $f_{E}, f_{V}$ and $f_{N}$ can be identical. In the similar fashion, equations for the case of higher direction of emissions such as five and nine can be written just by simply averaging the Doppler frequency shifts from opposite directions.

The sodar can be operated in single or multi-frequency mode. In multi-frequency mode MFAS sodar system can be configured for the frequencies from 1650 to $2750 \mathrm{~Hz}$. Sequences composed of pulses of different frequencies are emitted and the backscattered waves of all frequencies are received simultaneously. In the Aindanda measurement the sodar was configured for multi-frequency operation to achieve better signal-to-noise ratio.

\section{RESULTS}

The two weeks long observation made at Aindanda revealed that the boundary layer activities and hence the wind channeling through this pass has very strong diurnal periodicity, i.e., there is very little day-to-day variations. In this paper, we present the characteristics that are most likely to occur over the pass. In normal weather days during the early monsoon season sky of Kathmandu generally remains partly cloudy that may result into veryshort time partial or scattered precipitation. We chose the day of 13 June 2013 as it appears representative to the weather situations that is most likely to prevail in and around the Kathmandu valley.

\section{WIND STRUCTURE}

The facsimile plots of diurnal variation of wind speed and direction over the Aindanda low-mountain pass on 13 June 2013as produced by sodar has been depicted in Fig. 3. During the midnight (Fig. 3a), northeasterly wind prevails up to the height of $400 \mathrm{~m}$ above the ground level (AGL), which appears to be subdivided into three 
different layers. The lowest layer below 100m AGL blows with speed $5.3 \mathrm{~ms}^{-1}$, middle layer in between 100 and $300 \mathrm{~m} \mathrm{AGL}$ with speed $4.2 \mathrm{~ms}^{-1}$ and upper layer with speed $5.6 \mathrm{~ms}^{-1}$. In between 0100 and $0200 \mathrm{LST}$, the threelayer structure of the flow field continued to prevail but wind speed significantly decreased. The maximum speed of the wind in the lowest layer appeared to be around 3.5 $\mathrm{ms}^{-1}$ whereas $2.5 \mathrm{~ms}^{-1}$ in the middle and upper layers. It is interesting to note that the wind in lowest $200 \mathrm{~m} \mathrm{AGL}$ (lowest and middle layers) continued to remain easterly, whereas that above $200 \mathrm{~m}$ switched to southwesterly. In between 0200 and 0300 LST, the lowest $200 \mathrm{~m}$ AGL became almost calm with wind speed less than $0.6 \mathrm{~ms}^{-1}$ and it gradually increased to attain close to $2 \mathrm{~ms}^{-1}$ at the height of $650 \mathrm{~m}$ AGL. During this period, the wind direction profile (Fig. 3b) suggests that the lowest $50 \mathrm{~m}$ layer of the atmosphere continued to carry easterly wind while southwesterly prevailed from 50 to $100 \mathrm{~m}$ and again easterly lied between 100 to $200 \mathrm{~m}$ with southwesterly aloft.
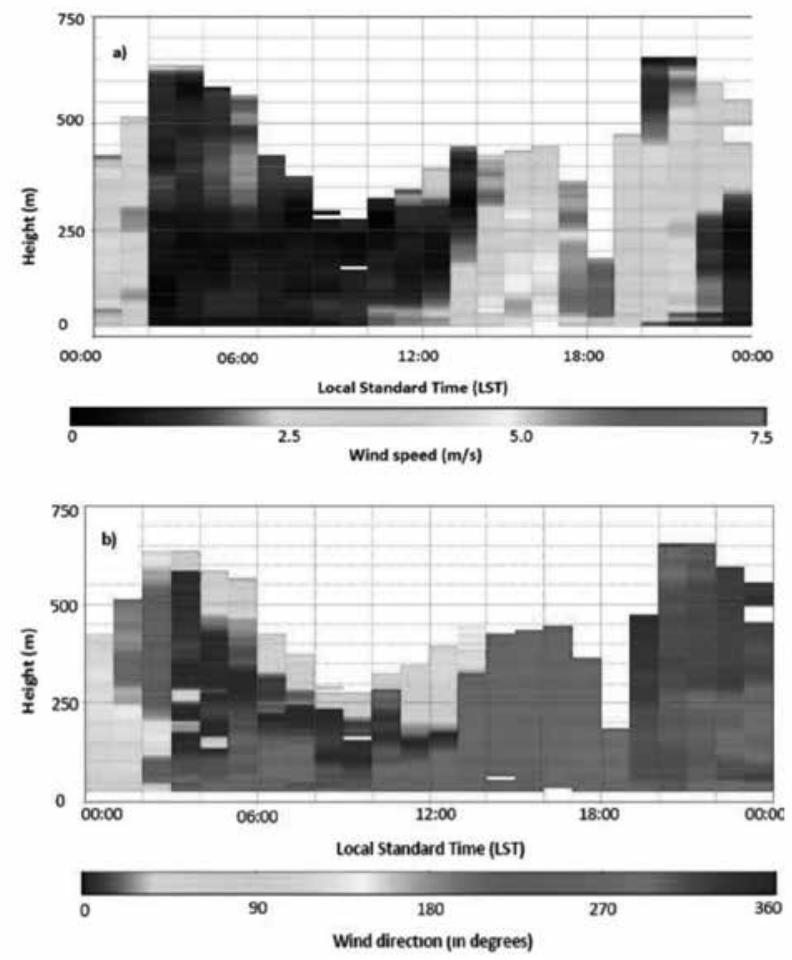

Fig. 3. Facsimile plots of wind speed (a) and wind direction (b) of Aindanda.

In between 0300 and 0600 LST, wind speed tended to increase with time from less than $0.5 \mathrm{~ms}^{-1}$ to about 1.1 $\mathrm{ms}^{-1}$ attaining its peak at about $100 \mathrm{~m}$ AGL and which decreased to $0.4 \mathrm{~ms}^{-1}$ at the height of $250 \mathrm{~m} \mathrm{AGL}$. In the layer above wind speed reached its maximum of around $1.9 \mathrm{~ms}^{-1}$ at $400 \mathrm{~m}$ AGL and thus showing distinct double layering structure (Fig. 4a). During the period, direction of the wind in the lowest $100 \mathrm{~m}$ appeared to be northwesterly topped by northerly/northeasterly up to the height of $600 \mathrm{~m}$ AGL and a very shallow easterly above $600 \mathrm{~m}$. The distribution of wind speed seems to be highly consistent with the understanding that the wind speed, in general, increases with height, reaching a maximum near the top of the stable boundary layer (Stull 1989). The flow pattern, both speed and direction appears to continue more or less the same way until 0800 LST except the layer between 30 to $200 \mathrm{~m}$ AGL flowed westerly and the probing height of sodar limited only up to the height of about 450m AGL.
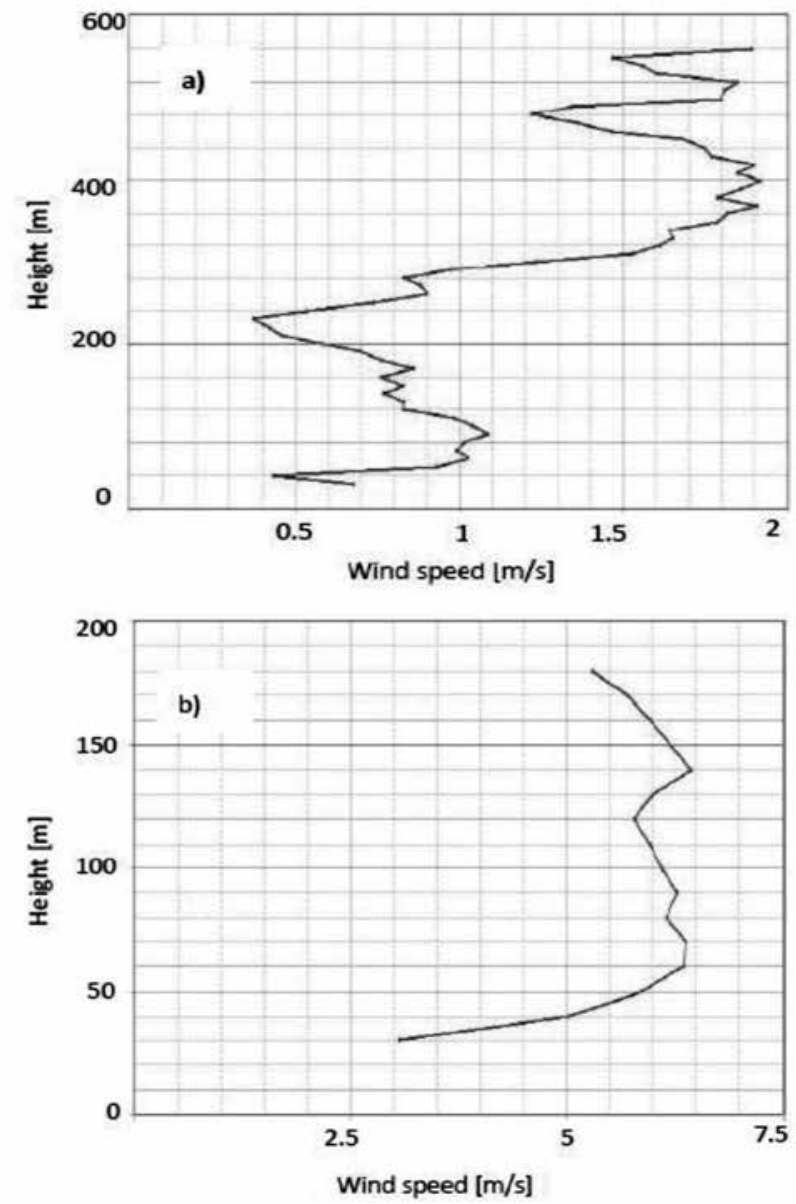

Fig. 4. Vertical profile of wind speed at 0600 LST (a) and 1900 LST (b).

Beyond 0800 LST, the wind speed of lowest $100 \mathrm{~m}$ layer quickly increased to about $1.4 \mathrm{~ms}^{-1}$ whereas above $100 \mathrm{~m}$ appeared to decrease gradually down to $0.4 \mathrm{~ms}^{-1}$. Wind passing through the pass remained to be westerly and northwesterly up to the height of $200 \mathrm{~m}$ capped by very shallow easterly layer from above. The same situation propagated until 1100 LST with westerly in the lowest $100 \mathrm{~m}$ topped by northwesterly up to the height of $300 \mathrm{~m}$ AGL and again topped by shallow easterly. 
At the noon as well a clear double layering of wind can be observed with westerly wind of about $2 \mathrm{~ms}^{-1}$ in the lowest $100 \mathrm{~m}$ AGL that decreased to about $0.5 \mathrm{~ms}^{-1}$ till it reaches around $200 \mathrm{~m}$ AGL and again increased as easterly to about $2 \mathrm{~ms}^{-1}$ at about $350 \mathrm{~m} \mathrm{AGL}$. As the afternoon progresses, speed of both layer increased keeping the profile shape nearly the same. The direction of the flow appears to be westerly up to the height of $150 \mathrm{~m}$ AGL and easterly prevails above this height. Beyond 1400 LST, the upper layer easterly/southeasterly seems to vanish and westerly wind starts to increase its speed further from $3 \mathrm{~ms}^{-1}$ below $100 \mathrm{~m}$ AGL reaching its maximum of $6.5 \mathrm{~ms}^{-1}$ by 1900 LST(Fig. 4b). The speed and direction profiles during these hours suggest that speed and depth of the high wind speed gradually increases with much higher speed close to the surface, particularly, below 100m AGL and keeping the direction of flow westerly from bottom up to the probing height (450m AGL).

After 1900 LST and until midnight the wind passing over through the Aindanda Pass remains to be northwesterly. However, wind speed beyond this time, tends to decrease rather quickly in the upper layer and slowly in the lower layer until 2200 LST. During the period, wind speed in the lowest $100 \mathrm{~m}$ AGL decreased to less than $3 \mathrm{~ms}^{-1}$. However, close to the midnight, while the speed in the lowest $200 \mathrm{~m}$ AGL decreased to less than $2 \mathrm{~ms}^{-1}$, in the wind above speed gradually increased to attain the value of about $3.6 \mathrm{~ms}^{-1}$ at the height of $450 \mathrm{~m} \mathrm{AGL}$. The dominance of northwesterly in direction with occasional northerly and westerly winds over the pass during the night can be expected to be terrain-forced flows (Whiteman 2000).

The diurnal pattern of wind speed and direction described above appears to repeat frequently during the two weeks of measurement with couple of exceptional days and may reflect the general tendency of flow pattern over the pass.

\section{MIXING LAYER HEIGHT}

The lowest part of the boundary layer of the atmosphere (Stull 1989) that executes significant vertical movements of air parcels causing an effective mixing of lower and upper layer air masses is identified as mixing layer. The depth of which is called the mixing layer height (MLH) enormously help understand and characterize the boundary layer. In this sub-section, we present the diurnal variation of MLH and try to assess the possible implications in the prevailing atmospheric conditions of the valley.

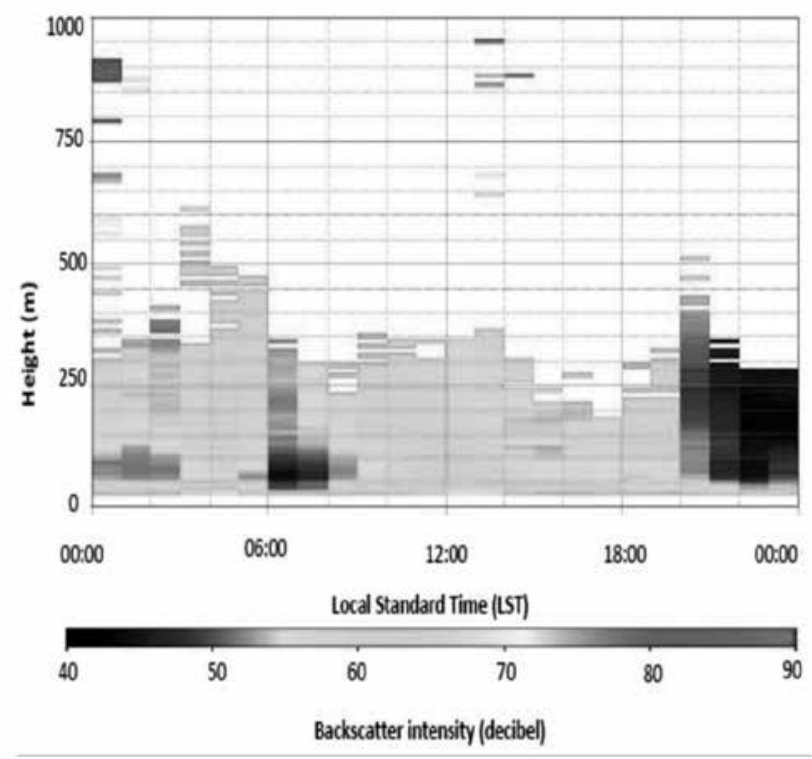

Fig. 5. Facsimile plot of backscattered intensity of acoustic signals.

Fig. 5 shows the facsimile of diurnal variation of the backscattered intensity that will be used as a supplement to sodar produced diurnal variation of MLH (Fig. 7b) for the analysis of characteristic behavior of MLH over the Aindanda Pass. Excluding the rather unusual trends of backscattered intensities and the data missing above $500 \mathrm{~m}$ AGL, where one can be skeptical, we discuss from what is apparent up to the height of 500m AGL.

The distribution of the backscattered intensities strongly suggests that the MLH over the pass undergoes an abrupt ascend and descend during night and early morning hours. During the period of 0000 LST to 0200LST, relatively high backscatter intensity signal is seen to descend from about 450m AGL down to the height at about $360 \mathrm{~m}$ AGL, which indicates the presence of mixing layer up this altitude. The MLH above the pass appears to descend quickly down to $130 \mathrm{~m}$ AGL at 0300 LST, which continues to fall to 120m AGL until 0300 LST to rise abruptly to the height of $520 \mathrm{~m}$ AGL by the time 0600 LST.

After sunrise, the fluctuations of stable layer height appear to be relatively suppressed suffering the rise and fall of not more than $170 \mathrm{~m}$ in each hour. In between 0600 to $1500 \mathrm{LST}$, relatively high backscattered intensity and hence the stably stratified layer lies at the top. During these sunlit hours MLH fluctuates in between 290 to $450 \mathrm{~m}$ AGL. Beyond 1500 LST, the MLH further drops down to $210 \mathrm{~m}$ AGL, rises immediately up to $280 \mathrm{~m}$ AGL and remains nearly constant till 1800LST. MLH then decreases to $170 \mathrm{~m}$ AGL at 1900 LST after sunset during 
which very strong westerly appears to intrude into the valley (Fig. 7). This short drop is followed by an abrupt increase in MLH to $710 \mathrm{~m}$ AGL at 2100 LST. However, this unusual increase is not expected and may be due to some reason not identified during the study. Close to the midnight, the MLH quickly drops down to about $120 \mathrm{~m}$ AGL. The diurnal pattern described above show strong diurnal periodicity for the couple of abnormal weather days during the period of measurement.

\section{COMPARISON AND IMPLICATION}

Though, present measurement is first of its kind in Aindanda, similar measurement were made at various places in and around the Kathmandu valley including Sanothimi that lies at the central area of the valley (Shrestha et al. 2015, Regmi \& Maharjan 2013, Regmi et al. 2003). The measurement together with numerical predictions made by Regmi et al. (2003) suggested that the MLH over the central area of the valley during day remains in between 700 to $900 \mathrm{~m}$ AGL capped by a stably stratified layer just above the surrounding mountaintops. The above assertion is further supported by the follow up like study by Panday (2006). As Aindanda Pass is situated at about $500 \mathrm{~m}$ from the valley floor in the western rim of the valley, we may expect the mixing height over the pass to be in between 200 to $400 \mathrm{~m}$ AGL in the afternoon time. Indeed, the diurnal variation of the MLH measured over the pass lies almost within this range. This should ensure that present observation has captured the essential features of the boundary layer evolution and associated activities.

The MLH developed over the Aindanda Pass can be thought to behave as an open window through which the cool density flow intrude into the weakly stratified MLH over the valley as westerly and northwesterly wind. Thus, the westerly or northwesterly winds intruding into the valley can have profound effect on the prevailing weather and climate over the valley. A comparative study of observed characteristics of boundary layer characteristics over the Aindanda and Sanothimi may help achieve better understanding of the boundary layer processes whether it be the atmospheric stratifications, air pollution transport, thermal comfort etc. in the valley. Figs. 3 and 6 show the diurnal variation of wind speeds and directions over the Aindanda and Sanothimi areas, respectively. Similarly, Figs. $7 \mathrm{a}$ and $7 \mathrm{~b}$, respectively, show the diurnal variation of MLH over Sanothimi and Aindanda.

If we closely examine the Fig. $3 \mathrm{a}$ and $7 \mathrm{a}$, it can be seen that Sanothimi area remains calm or windless during the midnight hours with wind speed that may vary from 0.5 to $2 \mathrm{~ms}^{-1}$ (Shrestha et al. 2015) whereas Aindanda appears relatively windy with speed that may vary from 3 to 6 $\mathrm{ms}^{-1}$. The lack of correlation between the flows over the valley bottom and the surrounding mountain pass strongly suggests that the valley air mass is well decoupled from the upper air masses (Peterson et al. 1990). Decoupling of valley air with the upper air appears to be a pleasurable interpretation for the discontinuity of the wind over Aindanda Pass and the valley bottom since the nocturnal boundary layer over Sanothimi is fully matured with the height of around $80 \mathrm{~m}$ AGL whereas that of Aindanda fluctuates at about $250 \mathrm{~m}$ during the same period.
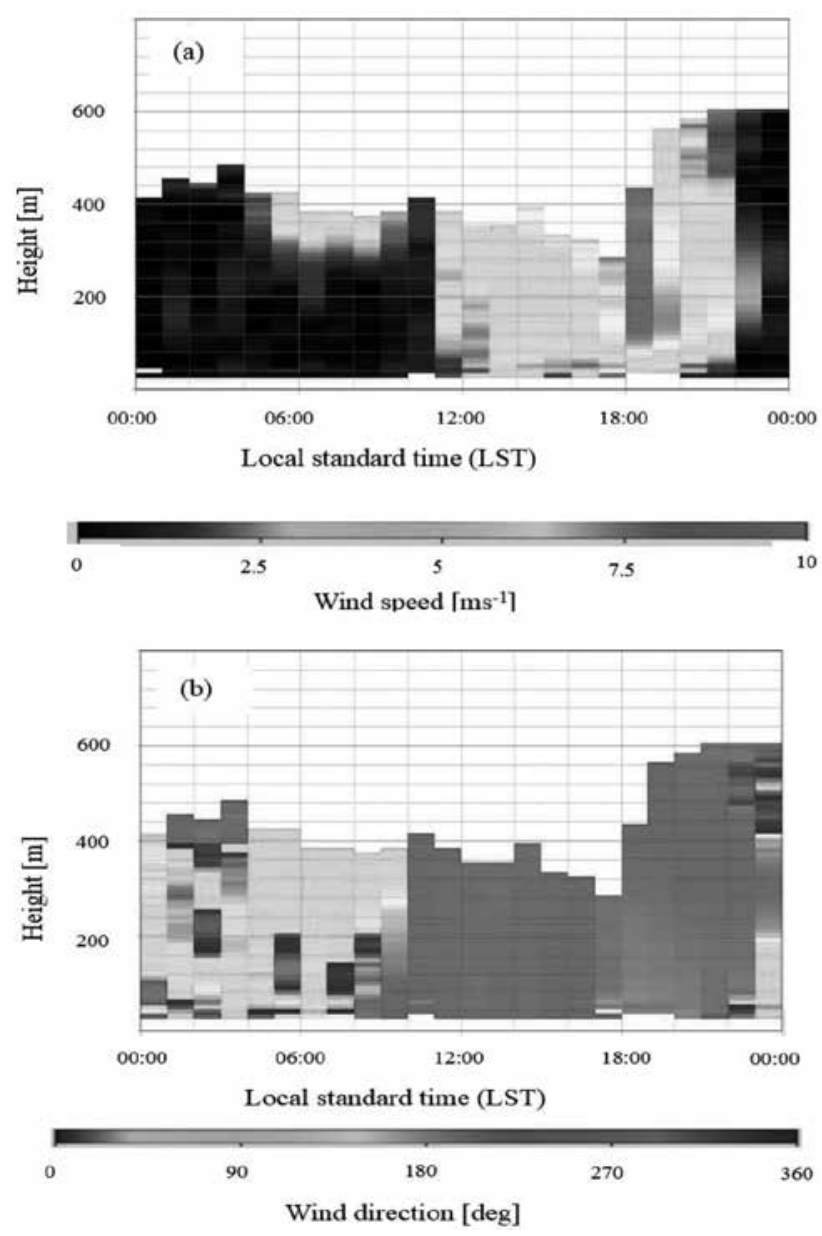

Fig. 6. Facsimile plots of hourly averaged (a) wind speed and (b) wind direction (Shrestha et al. 2015).

The so-called decoupling of valley air mass with that of upper level might have been resulted as follows. After sunset, the radiative cooling of surrounding mountain slopes initiate cool and dense air mass down in the slopes that gradually get accumulated in the bowl-shaped Kathmandu valley. The depth of the cold air pool so developed in the valley may reach up to the height of $400 \mathrm{~m}$ (Regmi et al. 2003) depending upon the season. The much shallower MLH over the central area of the valley indicates that the airmass aloft is highly stratified. The deep cold air pool sustain until sunrise since cool 
and dense air mass in the slopes of the surrounding mountains continue to pile up over the valley floor until then. The coincidence of spotting westerly above $400 \mathrm{~m}$ from the bottom of the valley in the central area (Figs. $6 \mathrm{a} \& \mathrm{~b}$ ) with calm and windless situation beneath and observing westerly over Aindanda Pass (Figs. 3a \& b) during nighttime leads us to conclude that the air mass over the valley is highly stratified up to that height.

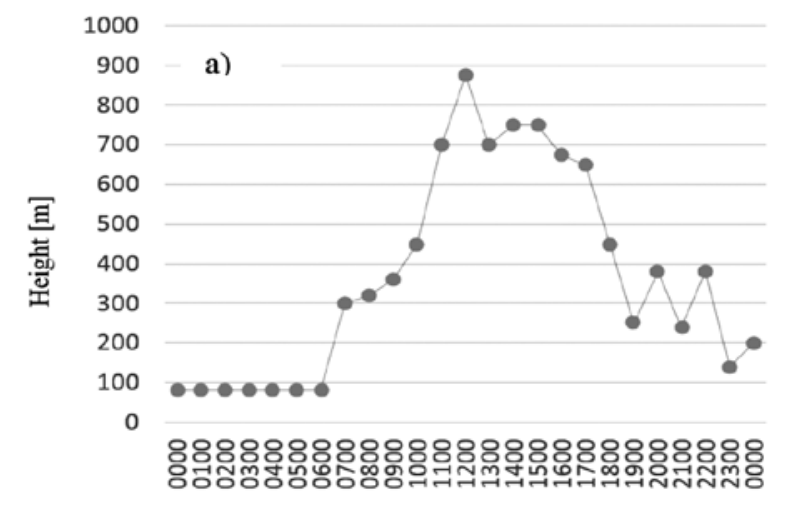

Local standard time (LST)

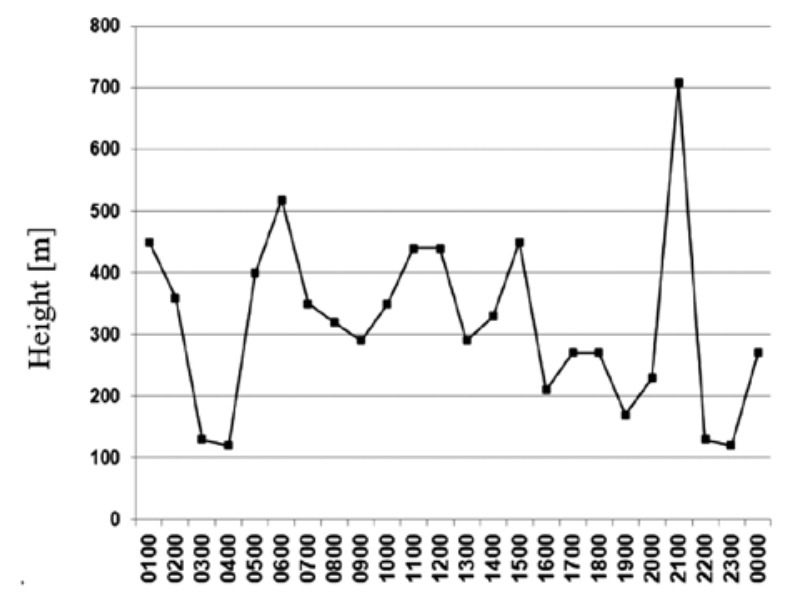

Local standard time (LST)

Fig. 7. Plot showing diurnal variation of MLH over Sanothimi (a) and Aindanda (b).

However, during the daytime, MLH of about 290 to $450 \mathrm{~m}$ AGL measured at Aindanda situated at about $500 \mathrm{~m}$ above the valley floor nicely corresponds to the MLH of about 700 to $900 \mathrm{~m}$ AGL measured from Sanothimi. The MLH measured in both the places correspond to the height of Aindanda (Mt. Nagarjun) in the west and Mt. Nagarkot in the east. It can thus be inferred that the Kathmandu valley is capped by stably stratified layer just above the surrounding mountaintops as numerically predicted by Regmi et al. (2003). In such situation, regional air masses can intrude into the valley in the form of shallow layer from the low-mountain passes such as Aindanda Pass that may accelerate in the lee of the mountain. The high westerly wind measured both in Aindanda Pass and Sanothimi during the late afternoon time (Fig. 3 and 6) suggest that the westerly/northwesterly channeled in by Aindanda Pass actually swipes out the Kathmandu valley floor and channel out from the eastern mountain passes. In consideration with the way the MLH develops over Aindanda Pass and over the central area of the valley and the direction as well as speed of winds, it can be said that the northwesterly or westerly wind over the Kathmandu valley is the cool density flow that intrudes into the weakly stable boundary layer of the valley.

The presence of stable layer just above the surrounding mountaintops and rather high wind speed measured during the late afternoon over the Aindanda Pass appear very consistent with the predictions of Regmi et al.(2003) who have argued that the westerly/northwesterly may show the nature of hydraulic jump like flow in the western part of the Kathmandu valley in the late afternoon. Such a flow can be hazardous for the light aircrafts. Thus, we speculate that the frequent severe discomfort and fatal accident could have been linked with not having knowledge of wind pattern that could possibly prevail over the pass.

\section{CONCLUSION}

The diurnal characteristics of boundary layer activities over the western low-mountain pass, Aindanda, of Kathmandu valley have been continuously monitored for two weeks during the early monsoon period by deploying a monostatic flat array sodar. The observation shows that the flow channeled into the Kathamandu valley by the pass predominantly remains westerly and northwesterly during the daytime whereas it drains air mass out of the valley during the nighttime. Speed of the westerly and northwesterly wind often exceeds $6.5 \mathrm{~ms}^{-1}$ during the late afternoon. Nighttime stable layer was highly fluctuating with an average height of around $300 \mathrm{~m}$ and daytime mixing layer height was suppressed limiting it in between $290-450 \mathrm{~m}$ above the ground in early part of the day but reduced to $210-270 \mathrm{~m}$ during the late afternoon. Comparison of diurnal variation of mixing layer height at Aindanda with that of the central area of the valley floor strongly suggests that air mass intruding into the Kathmandu valley through this pass is a cool density flow over the weakly stratified mixed layer of the valley. Development of nocturnal mixing layer at Aindanda seems independent while mixing depth during day is highly influenced by the mixing layer evolution of the valley supporting the argument that capping inversion defining the valley MLH covers area more than that of the valley along with surface based strong stable layer at the valley floor. The structure of the wind channeled through this pass indicates the possibility of making 
hydraulic jump in the western part of the Kathmandu valley, particularly, during the late afternoon time.

The inflows as such from all the regions surrounding the valley determine the valley meteorology implications to air quality measurement and aviation safety as well as study of Regmi et al. (2003) reports that the western part of Kathmandu valley undergoes hydraulic jump that needs to be yet verified in further studies.

Considerable relation in observation is obtained between that of Aindanda and Sanothimi though the observations were taken at different dates. Results obtained are in accordance to that produced in previous studies with some variations establishing their validity and thus shows the suitability of SODAR for characterizing atmospheric boundary layer of complex terrain like that of Kathmandu.

\section{ACKNOWLEDGEMENTS}

The research was carried out as continuation of research activities initiated with the Institutional Research Grants granted by the University Grants Commission (UGC), Nepal, for the project "Assessing Wind Electricity Potential in and around the Kathmandu Valley". We would also like to thank UGC and Nepal army for allowing us to carry sodar observations within their premises.

\section{REFERENCES}

Aggarwal, S.K., Singal, S.P., Kapoor, R.K. and Adiga, B.B. 1980. A study of atmospheric structures using sodar in relation to land and sea breezes. Boundary-Layer Meteorology 18: 361-371.

Argentini, S., Mastrantonio, G., Fiocco, G. and Ocone, R. 1992. Complexity of the wind field as observed by a sodar system and by automatic weather stations on the Nansen Ice Sheet, Antarctica, during summer 1988-89: Two case studies. Tellus 44B: 422-429.

Asimakopoulos, D.N., Helmis, C.G. and Michopoulos, J. 2004. Evaluation of SODAR methods for the determination of the atmospheric boundary layer mixing height. Meteorology and Atmospheric Physics 85: 85-92.

Bacci, P., Giraud, C., Longhetto, A. and Richiardone, R. 1984. Acoustic sounding of land and sea breezes. Boundary-Layer Meteorology 28: 187-192.

Beyrich, F. 1995. Mixing-height estimation in the convective boundary layer using sodar data. Boundary-Layer Meteorology 74: 1-18

Brown, E.H. and Hall, Jr. F.F. 1978. Advances in atmospheric acoustics. Reviews of Geophysics and Space Physics 16: 47-110.
Cheung, T.K. and Little, C.G. 1990. Meteorological tower, microbarograph array, and sodar observations of solitary-like waves in the nocturnal boundary layer. Journal of the Atmospheric Sciences 47: 2516-2536.

Clifford, S.F., Kaimal, J.C., Lataitis, R.J. and Strauch, R.G. 1994. Ground-based remote profiling in atmospheric studies: An overview. Proceedings of the IEEE 82:313-355.

Coulter, R.L. 1979. A comparison of three methods for measuring mixing-layer height. Journal of Applied Meteorology 18: 1495-1499.

Einaudi, F., Clark, W.L., Fua, D., Green, J.L. and VanZandt, T.E.1987. Gravity waves and convection in Colorado during July 1983. Journal of the Atmospheric Sciences 44: 15341553.

Emeis, S., Schäfer, K. and Münkel, C. 2008. Surfacebased remote sensing of the mixing-layer height - a review- Meteorologische Zeitschrift 17: 621630.

Gera, B.S. and Weill, A. 1987. Doppler sodar analysis of frontal friction in relation to frontal slope. Journal of Climate and Applied Meteorology 26: 885-891.

Gera, B.S. and Weill A. 1991. Doppler sodar observations of the boundary layer parameters and a frontal system during the "MESOGERS 84 " experiment. Boundary-Layer Meteorology 54: 41-57.

Greenhut, G.K. and Mastrantonio, G. 1989. Turbulence kinetic energy budget profiles derived from Doppler sodar measurements. Journal of Applied Meteorology 28: 99-106.

Gudiksen, P.H., Leone Jr., J.M., King, C.W., Ruffieux, D. and Neff, W.D. 1992. Measurements and modeling of the effects of ambient meteorology on nocturnal drainage flows. Journal of Applied Meteorology 31: 1023-1032.

Kataoka, T., Takehisa, M., Ito, Y. and Mitsuta, Y. 1991. A lowlevel jet observed by a Doppler sodar during the International Sodar Intercomparison Experiment (ISIE). Journal of the Meteorological Society of Japan 69: 171-177.

King, J.C., Mobbs, S.D., Rees, J.M., Anderson, P.S. and Culf, A.D. 1989. The stable Antarctic boundary layer experiment at Halley station. Weather 44: 398-405.

Kotroni, V., Lemaitre, Y. and Petitdidier, M. 1994. Dynamics of a low-level jet observed during the Fronts 87 experiment. Quarterly Journal of the Royal Meteorological Society 120: 277-303. 
Moulsley, T.J., Asimakopoulos, D.N., Cole, R.S., Crease, B.A. and Caughey, S.J. 1981. Measurement of boundary layer structure parameter profiles by acoustic sounding and comparison with direct measurements. Quarterly Journal of the Royal Meteorological Society 107: 203-230.

Neff, W.D. 1986. On the use of sodars to study stably stratified flow influenced by terrain. Atmospheric Research 20: 279-308.

Neff, W.D. 1988. Observations of complex terrain flows using acoustic sounders: Echo interpretation. Boundary-Layer Meteorology 4: 207-228.

Neff, W.D. 1990. Remote sensing of atmospheric processes over complex terrain. Atmospheric Processes over Complex Terrain (Meteorological Monographs) ed. Blumen, W. American Meteorological Society, Boston. 23(45): 173228p.

Neff, W.D. and Coulter, R.L. 1986. Acoustic remote sensing. Probing the Atmospheric Boundary Layer. (ed.) Lens-chow, D.H. American Meteorological Society. 201-239p.

Neff, W.D. and King, C.W. 1987. Observations of complex terrain flows using acoustic sounders: Experiments, Topography and Winds. BoundaryLayer Meteorology 40: 363-392.

Neff, W.D. and King, C.W. 1988. Observations of complex terrain flows using acoustic sounders: Drainage flow structure and evolution. Boundary-Layer Meteorology 43: 15-41.

Panday, A.K. 2006. The Diurnal Cycle of Air Pollution in the Kathmandu Valley, Nepal. PhD Thesis, Department of Earth, Atmospheric and Planetary Sciences, Massachusetts Institute of Technology, U.S.A.

Peterson, T.C, Grant, L.O., Cotton, W.R. and Rogers, D.C. 1990. The effect of decoupled Low-Level Flow on Winter Orographic Clouds and precipitation in the Yampa River Valley, Journal of Applied Meteorology 30: 368-386.

Prakash, J.W.J., Ramachandran, R., Nair, K.N., Sen Gupta, K. and Kunhikrishnan, P.K. 1992. On the structure of sea-breeze fronts observed near the coastline of Thumba, India. Boundary-Layer Meteorology 59: 111-124.
Ralph, F.M., Mazaudier, C., Crochet, M. and Venkateswaran, S.V. 1993. Doppler sodar and radar wind-profiler observations of gravitywave activity associated with a gravity current. Monthly Weather Review 121: 444-463.

Regmi, R.P., Kitada, T. and Kurata, G. 2003. Numerical Simulation of Late Wintertime Local Flows in Kathmandu Valley, Nepal: Implication for Air Pollution Transport, Journal of Applied Meteorology 42: 389- 403.

Russell, P.B. and Uthe E.E. 1978. Regional patterns of mixing depth and stability: Sodar network measurements for input to air quality models. Bulletin of the American Meteorological Society 59: 1275-1287.

Sen Gupta, K., Kunhikrishnan, P.K., Radhika, V. and Nair, K.N. 1986. Estimating surface sensible heat flux using sodar and surface temperature measurements in the evolving convective boundary layer. Atmospheric Research 20: 119123.

Shrestha, S., Shrestha, S., Maharjan, S. and Regmi, R.P. 2015. Boundary layer characteristics over central area of the Kathmandu valley as revealed by sodar observations. Journal of Institute of Science and Technology 20(1): (accepted).

Singal, S.P., Gera, B.S. and Aggarwal, S.K. 1982. Determination of structure parameters using sodar. Boundary-Layer Meteorology 23: 105114.

Stull, R.B. 1989. An Introduction To Boundary Layer Meteorology. Kluwer Academic Publishers, Dordrecht/ Boston/London, 2p.

Weill, A. and Coauthors, 1988. A mesoscale shear convective cell observed during the COAST Experiment: Acoustic sounder measurements. Boundary-Layer Meteorology 44: 359-371.

Whiteman, C.D. 2000. Mountain Meteorology. Oxford University Press, New York, 141p. 